\title{
Screening breast magnetic resonance imaging in women with hormone replacement therapy
}

Feng Zhang ${ }^{1,2^{*}} \mathbb{D}$, Qingjing Feng ${ }^{3}$, Zhiyong Zhang ${ }^{1}$, Yanjun $\mathrm{Hu}^{4}$ and Zhifeng Zhang ${ }^{2}$

\begin{abstract}
Objective: The objective of this study was to compare the performance of screening mammography versus magnetic resonance imaging (MRI) in hormone replacement therapy (HRT) users.

Methods: We performed a retrospective review of 4628 women who had mammography or breast MRI screening from the beginning of HRT use at three institutions from April 2005 to December 2015. Information of demographics, number of biopsies performed and pathologic outcomes were collected. Sensitivity, specificity, negative predictive value (NPV) and positive predictive value (PPV) of screening mammography and MRI were compared.

Results: Totally 11,540 screening studies were collected, including 9580 mammography studies and 1960 MRI studies. Breast cancer was diagnosed in 26 patients. Of the 26 cancers, MRI detected 24 and mammography detected 15. For mammography, the sensitivity, specificity, PPV, and NPV were $57.7 \%, 99.1 \%, 14.6 \%$, and $99.9 \%$, respectively; for $\mathrm{MRI}$, those values were $92 \%, 92.5 \%, 14.2 \%$, and $99.9 \%$, respectively. MRI screening was much more sensitive than mammography screening ( $p<0.05,92 \%$ vs $57.7 \%)$. There was no difference of specificity, PPV and NPV between two modalities.
\end{abstract}

Conclusions: Our data showed that screening breast MRI may be a useful adjunct modality of mammography in HRT users.

Keywords: Hormone replacement therapy, Magnetic resonance imaging, Mammography, Breast cancer, Ductal carcinomas in situ

\section{Introduction}

The use of HRT has increased rapidly in China due to the expansion of the population of premature ovarian failure (POF) and more attention being paid to the side effects of menopause [1]. However, in many Western countries, influenced by the report from the first Women's Health Initiative (WHI) randomized study, which concluded that the use of HRT was related to an increased risk of breast cancer, a cliff-like drop of HRT consumption was seen [2]. Subsequently, a decline in breast cancer incidence was also observed after the drop in HRT consumption in

\footnotetext{
*Correspondence: zhang3772@qq.com

${ }^{2}$ Department of Reproductive Endocrinology, Hangzhou Women's

Hospital, Kunpeng Road 369, Hangzhou 310008, China

Full list of author information is available at the end of the article
}

many countries [3]. Rudolph et al. proposed that modifications in gene polymorphisms related to solute transportation of mitochondria, immune response activation and transmembrane signaling are the possible explanation for the increased breast cancer risk [4].

Mammography is the primary screening modality to detect breast malignancy in the general population [5]. While for women who have the BRCA gene mutation, at least two first- or second-degree relatives with breast or ovarian cancer history and chest radiation history are recommended for mammography plus MRI screening annually [6]. Until now, scarce information has been available for the ideal screening modality in a non-highrisk or average high-risk population such as HRT users.

Although there are still disputes about the link between HRT and breast cancer, women taking HRT have always

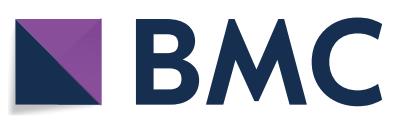

(c) The Author(s) 2018. This article is distributed under the terms of the Creative Commons Attribution 4.0 International License (http://creativecommons.org/licenses/by/4.0/), which permits unrestricted use, distribution, and reproduction in any medium, provided you give appropriate credit to the original author(s) and the source, provide a link to the Creative Commons license, and indicate if changes were made. The Creative Commons Public Domain Dedication waiver (http://creativecommons.org/ publicdomain/zero/1.0/) applies to the data made available in this article, unless otherwise stated. 
been afraid of increased breast cancer risk and would prefer annual breast cancer screening. Here, we study the performance of mammography and MRI screening in HRT users.

\section{Materials and methods}

A retrospective review was completed on patients who had mammography or breast MRI screening after the beginning of HRT use at Hangzhou Women's hospital, Zhejiang Provincial Women's Hospital and Yiwu Maternity and Child Care Hospital from April 2005 to December 2015. The data of the screening studies, tissue biopsies, and pathologic findings were collected.

Comparisons of sensitivity, specificity, PPV, and NPV between mammography and MRI groups were performed using Fisher's exact test and the methods described by Moscovitz [7].

\section{Results}

Of 4628 HRT users, the mean age at the beginning of HRT use was $48 \pm 4.1$ years (range $43-56$ years). The mean duration was $3.5 \pm 1.8$ years (range $1.2-6.5$ years). All HRT users had mammography or breast MRI screening at least once after the beginning of HRT. There were 11,540 screening studies performed totally, including 9580 mammography studies and 1960 MRI studies.

There were 451 MRI studies and 2625 mammograms were assessed 1-2 by the Breast Imaging Reporting and Data System (BI-RADS) category. A total of 1364 MRI studies and 6867 mammograms got results of BIRADS 3. There were 145 MRI studies and 88 mammograms were reported BI-RADS 4-5. Biopsy was made for all of those patients with BI-RADS 4-5. In total, there were 164 biopsies (3.5\% of all patients), including 105 excisional biopsies and 59 core biopsies. There were 18 women assessed BI-RADS $1-3$ by mammography while MRI were assessed BI-RADS 4-5. Pathology results from biopsy revealed eleven cancers (MRI true-positive) and seven benign results (MRI false-positive). There were six women assessed BI-RADS $1-3$ by MRI while mammography were assessed BI-RADS 4-5. Pathology results from biopsy revealed two ductal carcinoma in situ (DCIS) and four benign results.

Of 4628 patients, 26 were diagnosed of breast malignancy. Of 26 cancers, 6 were diagnosed of DCIS and 20 were diagnosed of invasive breast cancers. Only one woman with interval cancer who had a negative mammography result at screening and touched a hard mass 6 months later that was diagnosed malignant by biopsy. Of 26 cancers, MRI detected 24 cancers and mammography detected 15 cancers. MRI missed only two cancers.

The sensitivity of MRI (92\%) was significantly higher than mammography $(57.7 \%)(p<0.05)$. The comparison of specificity, NPV and PPV between mammography and MRI had no statistical significance (see Table 1).

\section{Discussion}

Mammography was usually done as the primary modality for breast cancer screening, while for those at a high risk, MRI took priority over mammography $[6,8]$. Since scarce information is available for the ideal screening modality for average-risk patients like HRT users, the performance of mammography and MRI screening in women HRT users were compared in our study.

Although some disputes exist based on three large epidemiology studies, it was concluded that the risk of breast cancer increased with exposure to combination HRT $[9,10]$. Lee et al. [11] proposed that the odds ratio (OR) could increase by $7.6 \%$ for each year of combination HRT use linearly. And at the tenth year, the HR could reach between 1.5 and 2.5. The relationship of HRT and breast cancer risk was established mainly for the phenomenon that breast cancer incidence decreased after the decline of HRT use, which was observed in many countries [12].

Studies demonstrated that no effect of HRT use was observed in younger women ( $<50$ years) and the HR of breast cancer following HRT use increased with age at first use [13]. More than half of breast cancer patients in Western countries were older than 50 or postmenopausal when diagnosed, while most patients in China were under 50 years old or premenopausal. The mean age of this cohort at the beginning of HRT use was $48 \pm 4.1$ years (range $43-56$ years). That means there may be some differences in the population between China and Western countries. The results of Korean and Japanese studies indicated women who received HRT had no increase of breast cancer risk $[14,15]$. Hou et al. [16] also suggested that different populations might have various breast cancer risks from HRT. They further concluded that Asian women with low BMI and dense breasts were associated with greater risk than other populations.

Although HRT use may decrease sensitivity and specificity of mammography, it still is the first choice for breast cancer screening for those patients $[17,18]$.

Table 1 Diagnostic performance of screening MRI and mammography in HRT users

\begin{tabular}{lcll}
\hline & MRI $(\mathbf{9 5} \% \mathbf{C l})$ & Mammography I $(\mathbf{9 5 \%} \mathbf{C l})$ & $\boldsymbol{p}$ \\
\hline Sensitivity & $92(85-96)$ & $57.7(52.4-65.4)$ & 0.03 \\
Specificity & $92.5(87.6-95.2)$ & $99.1(93.8-99.5)$ & 0.26 \\
PPV & $14.2(11.1-19.1)$ & $14.6(10.8-19.9)$ & 0.94 \\
NPV & $99.9(92.8-99.9)$ & $99.9(93.4-99.9)$ & 0.96 \\
\hline
\end{tabular}

$N P V$ negative predictive value, $P P V$ positive predictive value, $M R I$ magnetic resonance imaging 
Until now, there has been no reporting on MRI screening in HRT users. In our study, MRI had significantly higher sensitivity than mammography $(p<0.05,92 \%$ vs. $57.7 \%)$. There were 11 cancers $(42 \%)$ found by MRI alone. Mammography detected only two additional cancers. MRI had a higher false-positive rate and was less specific than mammography [19]. In our study, the negative-positive patients in MRI screening were 145 and in mammography were 88 . The specificities were $92.5 \%$ and $99.1 \%$ of MRI and mammography, respectively. There was no statistical significance of specificity, PPV, and NPV between two modalities.

PPV was low in both mammography and MRI modalities in our study. The possible explanation may be that Chinese women have smaller-size breast and denser breast tissue, who were younger than western women when menopause occurred. The mean age of the cohort of this study at the beginning of HRT use was $48 \pm 4.1$ years (range $43-56$ years). Chinese women had high rate of fibroadenomas and fibrocystic proliferation in their breasts, which raised the suspicion of malignancy.

There were six diagnoses of DCIS in our study. Four were detected by MRI and only two were detected by mammography. According to prior studies, MRI was superior to mammography in detecting DCIS [20]. Our study confirmed this conclusion. Two DCIS patients presented micro-calcifications in mammography, which could be detected more reliably by mammography than MRI [21].

The debate about the application of MRI in screening mainly focuses on its low positive biopsy, increased callback, greater cost than mammography, and poor patient compliance $[22,23]$. MRI detection needs a lot of time, requires the injection of intravenous gadolinium, and many patients experience claustrophobia in the MRI device. In our cohort, only about 600 patients received MRI as a screening modality, about one-eighth of all HRT users. There were 164 biopsies performed (3.5\% of all patients), including 105 excisional biopsies and 59 core biopsies. Benign pathological results included fibroadenomas, fibrocystic proliferation, atypia and complex sclerosing lesions.

The main limitation of our study was its retrospective design. The patients had random time intervals between mammography and MRI screening rounds. They also had random HRT use durations. It is hard to calculate the real duration of drug usage, which also made it difficult to tell whether or not the occurrence of breast cancer was due to HRT use. Many patients may choose combined screening modality such as ultrasound, mammography, and MRI. And some may choose 1, 2, or all 3, which limits the ability to compare mammography and MRI.

In conclusion, our study confirmed that breast MRI in HRT users was more sensitive than mammography.
Because MRI was seldom taken as a screening modality alone, it could be a useful adjunctive modality with mammography in screening. When physicians recommend a screening mode to HRT users, they should pay attention to the benefit and deficiency of MRI screening, especially for women who are younger at menopause and have denser breast tissue.

\section{Abbreviations}

MRI: magnetic resonance imaging; HRT: hormone replacement therapy; NPV: negative predictive value; PPV: positive predictive value; POF: premature ovarian failure; WHI: Women's Health Initiative; BI-RADS: breast imaging reporting and data system; DCIS: ductal carcinoma in situ; OR: odds ratio.

\section{Authors' contributions}

FZ: wrote the paper, conceived and designed the study; FZ; ZZ: contributed, analyzed and interpreted the data; $\mathrm{QF} ; \mathrm{ZZ} ; \mathrm{YH}$ : contributed and analyzed data. All authors read and approved the final manuscript.

\section{Author details}

1 Department of Breast Surgery, Hangzhou Women's Hospital, Hangzhou 310008, China. ${ }^{2}$ Department of Reproductive Endocrinology, Hangzhou Women's Hospital, Kunpeng Road 369, Hangzhou 310008, China. ${ }^{3}$ Department of Breast Surgery, Yiwu Maternity and Child Care Hospital, Yiwu 322000, China. ${ }^{4}$ Reproductive Endocrinology, Women's Hospital, School of Medicine, Zhejiang University, Hangzhou 310006, China.

\section{Acknowledgements}

Not applicable.

\section{Competing interests}

The authors declare that they have no competing interests.

\section{Availability of data and materials}

The datasets used and/or analyzed during the current study are available from the corresponding author on reasonable request.

\section{Consent for publication}

Not applicable.

Ethics approval and consent to participate

Not applicable.

Funding

Hangzhou social development project (20170533B60).

\section{Publisher's Note}

Springer Nature remains neutral with regard to jurisdictional claims in published maps and institutional affiliations.

Received: 7 August 2017 Accepted: 16 October 2018

Published online: 20 October 2018

\section{References}

1. Wang Y, Yang X, Li X, He X, Zhao Y. Knowledge and personal use of menopausal hormone therapy among Chinese obstetrician-gynecologists: results of a survey. Menopause. 2014;21(11):1190-6.

2. Rossouw JE, Anderson GL, Prentice RL, Writing Group for the Women's Health Initiative Investigators, et al. Risks and benefits of estrogen plus progestin in healthy postmenopausal women: principal results from the Women's Health Initiative randomized controlled trial. JAMA. 2002;288(3):321-33 
3. Zbuk K, Anand SS. Declining incidence of breast cancer after decreased use of hormone-replacement therapy: magnitude and time lags in different countries. J Epidemiol Community Health. 2012;66(1):17.

4. Rudolph A, Hein R, Lindström S, Breast Cancer Association Consortium, et al. Genetic modifiers of menopausal hormone replacement therapy and breast cancer risk: a genome-wide interaction study. Endocr Relat Cancer. 2013;20(6):875-87.

5. U.S. Preventive Services Task Force (uspstf). Breast Cancer: Screening [final update summary, Web page]. Rockville: uspstf; 2015. http://www.uspre ventiveservicestaskforce.org/Page/Document/UpdateSummaryFinal/ breast-cancer-screening. Accessed 31 Aug 2015.

6. Saslow D, Boetes C, Burke W, on behalf of the American Cancer Society Breast Cancer Advisory Group, et al. American Cancer Society guidelines for breast screening with MRI as an adjunct to mammography. CA Cancer J Clin. 2007;57(2):75-89.

7. Moskowitz CS, Pepe MS. Comparing the predictive values of diagnostic tests: sample size and analysis for paired study designs. Clin Trials. 2006;3(3):272-9.

8. Lehman CD. Role of MRI in screening women at high risk for breast cancer. J Magn Reson Imaging. 2006;24(5):964-70. https://doi.org/10.1002/ jmri.20752.

9. Beral V, Million Women Study Collaborators. Breast cancer and hormone-replacement therapy in the Million Women Study. Lancet. 2003;362(9382):419-27.

10. Collaborative Group on Hormonal Factors in Breast Cancer. Breast cancer and hormone replacement therapy: collaborative reanalysis of data from 51 epidemiological studies of 52,705 women with breast cancer and 108,411 women without breast cancer. Lancet 1997;350(9084):1047-59.

11. Lee SA, Ross RK, Pike MC. An overview of menopausal oestrogenprogestin hormone therapy and breast cancer risk. Br J Cancer. 2005:92(11):2049-58.

12. Kumle M. Declining breast cancer incidence and decreased HRT use. Lancet. 2008;372(9639):608-10.

13. Ewertz $M$, Mellemkjaer $L$, Poulsen $A H$, et al. Hormone use for menopausal symptoms and risk of breast cancer. A Danish cohort study. Br J Cancer. 2005:92(7):1293-7.
14. Saeki T Sano M, Komoike $Y$, et al. No increase of breast cancer incidence in Japanese women who received hormone replacement therapy: overview of a case-control study of breast cancer risk in Japan. Int J Clin Oncol. 2008;13(1):8-11

15. Bae JM, Kim EH. Hormone replacement therapy and risk of breast cancer in korean women: a quantitative systematic review. J Prev Med Public Health. 2015;48(5):225-30.

16. Hou N, Hong S, Wang W, Olopade Ol, Dignam JJ, Huo D. Hormone replacement therapy and breast cancer: heterogeneous risks by race, weight, and breast density. J Natl Cancer Inst. 2013;105(18):1365-72.

17. Hofvind S, Moller B, Thoresen S, Ursin G. Use of hormone therapy and risk of breast cancer detected at screening and between mammographic screens. Int J Cancer. 2006;118(12):3112-7.

18. Roman R, Sala M, Salas D, Ascunce N, Zubizarreta R, Castells X. Effect of protocol-related variables and women's characteristics on the cumulative false-positive risk in breast cancer screening. Ann Oncol. 2012;23(1):104-11.

19. Kriege M, Brekelmans $C T$, Boetes $C$, Magnetic Resonance Imaging Screening Study Group, et al. Efficacy of MRI and mammography for breastcancer screening in women with a familial or genetic predisposition. N Engl J Med. 2004;351(5):427-37.

20. Warner E, Causer PA, Wong JW, et al. Improvement in DCIS detection rates by MRI over time in a high-risk breast screening study. Breast J. 2011;17(1):9-17.

21. Gajdos C, Tartter PI, Bleiweiss IJ, et al. Mammographic appearance of nonpalpable breast cancer reflects pathologic characteristics. Ann Surg. 2002;235(2):246-51.

22. Berg WA, Blume JD, Cormack JB, ACRIN 6666 Investigators, et al. Combined screening with ultrasound and mammography vs mammography alone in women at elevated risk of breast cancer. JAMA. 2008;299(18):2151-63.

23. Leach MO, Boggis C, Dixon A, MARIBS Study Group, et al. Screening with magnetic resonance imaging and mammography of a UK population at high familial risk of breast cancer: a prospective multicentre cohort study (MARIBS). Lancet. 2005;365(9473):1769-78.
Ready to submit your research? Choose BMC and benefit from:

- fast, convenient online submission

- thorough peer review by experienced researchers in your field

- rapid publication on acceptance

- support for research data, including large and complex data types

- gold Open Access which fosters wider collaboration and increased citations

- maximum visibility for your research: over $100 \mathrm{M}$ website views per year

At $\mathrm{BMC}$, research is always in progress.

Learn more biomedcentral.com/submissions 